\title{
CrimRxiv
}

\section{Mirage of Police Reform: Procedural Justice and Police Legitimacy}

Robert E. Worden, Sarah J. McLean

Published on: Jul 01, 2017

License: Creative Commons Attribution 4.0 International License (CC-BY 4.0). 
